\title{
High-throughput fluorescent-based NKCC functional assay in adherent epithelial cells
}

\author{
Monica Carmosino ${ }^{1,2^{*}}$, Federica Rizzo ${ }^{1}$, Silvia Torretta ${ }^{1}$, Giuseppe Procino ${ }^{1}$ and Maria Svelto ${ }^{1}$
}

\begin{abstract}
Background: The kidney-specific NKCC cotransporter isoform NKCC2 is involved in the $\mathrm{Na}^{+}$reabsorption in the Thich Ascending Limb (TAL) cells and in the regulation of body fluid volume. In contrast, the isoform NKCC1 represents the major pathway for $\mathrm{Cl}^{-}$entry in endothelial cells, playing a crucial role in cell volume regulation and vascular tone. Importantly, both NKCC isoforms are involved in the regulation of blood pressure and represent important potential drug targets for the treatment of hypertension.

Results: Taking advantage of an existing Thallium $\left(\mathrm{Tl}^{+}\right)$-based kit, we set up a $\mathrm{Tl}^{+}$influx-based fluorescent assay, that can accurately and rapidly measure NKCC transporter activity in adherent epithelial cells using the high-throughput Flex station device. We assessed the feasibility of this assay in the renal epithelial LLC-PK1 cells stably transfected with a previously characterized chimeric NKCC2 construct (c-NKCC2). We demonstrated that the assay is highly reproducible, offers high temporal resolution of NKCC-mediated ion flux profiles and, importantly, being a continuous assay, it offers improved sensitivity over previous endpoint NKCC functional assays.

Conclusions: So far the screening of NKCC transporters activity has been done by ${ }^{86} \mathrm{Rb}^{+}$influx assays. Indeed, a fluorescence-based high-throughput screening method for testing NKCC inhibitors would be extremely useful in the development and characterization of new anti-hypertensive drugs.
\end{abstract}

Keywords: NKCC activity, Fluorescent assay, High-throughput, Drug screening

\section{Background}

The $\mathrm{Na}-\mathrm{K}-2 \mathrm{Cl}$ cotransporters, NKCC1 and NKCC2, are members of the superfamily of electroneutral cationcoupled co-transporters $(S L C 12 A)$, playing crucial roles in the cellular and body fluid homeostasis.

Located in the apical membrane and subapical vesicles in the thick ascending limb of the Henle's loop in the mammalian kidney, NKCC2 is responsible for reabsorbing about $20 \%$ of filtered $\mathrm{NaCl}$. In the macula densa it is also essential for tubuloglomerular feedback, the cross talk mechanism that finely tunes tubular reabsorption in response to variations of the glomerular filtration rate. Indeed, NKCC2 plays key roles in regulating body salt levels and blood pressure $[1,2]$. NKCC2 is the pharmacological site of action for loop diuretics; defects in its operation

\footnotetext{
* Correspondence: monica.carmosino@uniba.it

${ }^{1}$ Department of Biosciences, Biotechnologies and Biopharmaceutics, University of Bari, Via Amendola 165/A, 70126, Bari, Italy

2Department of Sciences, University of Basilicata, Via dell'Ateneo Lucano, 85100, Potenza, Italy
}

(c) 2013 Carmosino et al.; licensee BioMed Central Ltd. This is an Open Access article distributed under the terms of the Creative Commons Attribution License (http://creativecommons.org/licenses/by/2.0), which permits unrestricted use, distribution, and reproduction in any medium, provided the original work is properly cited. ute to the onset of essential hypertension.

Despite its importance, relatively little work has been carried out on NKCC2, mainly due to difficulties in expressing $\mathrm{NKCC} 2$ in a functionally-competent form in epithelial cells [3,4]. Indeed, chimeric [5,6] or tagged [7] recombinant proteins have been functionally expressed in mammalian cells and in Xenopus oocytes. These studies provided important information about transport kinetics and ion affinities $[8,9]$ displayed by different NKCC2 constructs.

Most of the information on the activity of NKCC2 is deduced from that of NKCC1 due to the high homology on the behavior of this closely related isoform, which has been successfully expressed in cultured cells and extensively studied.

NKCC1 represents the major pathway for $\mathrm{Cl}^{-}$entry in mammalian cells, playing a crucial role in cell volume regulation [10]. NKCC1 is also involved in the pathological secretion of cystic fluid in the Autosomal Polycystic Kidney disease [11] and modulator of vascular tone [12]. 
The functional studies of both NKCC1, NKCC2 and NKCC1/NKCC2 chimeric constructs have been performed so far using the ${ }^{86} \mathrm{Rb}^{+}$assay [13-15] or, alternatively, the NKCC-mediated $\mathrm{NH}_{4}{ }^{+}$uptake assay measured with a $\mathrm{pH}$-sensitive fluorescent dye [16].

$\mathrm{Rb}^{+}$is the closest-related potassium analog and its isotope (86) is characterized by the emission of highenergy $\beta$ and $\gamma$ radiations, which allow its quantification by Cerenkov counting without the need of liquid scintillation fluid addition.

However, the principal drawback of ${ }^{86} \mathrm{Rb}^{+}$lies in the potential toxicity and health hazard associated with radioactivity. As a consequence, many labs are reluctant to use the ${ }^{86} \mathrm{Rb}^{+}$-based radioactive flux assay format for the analysis of NKCC activity.

Alternatively, ${ }^{86} \mathrm{Rb}^{+}$isotope can be substituted with non-radioactive ${ }^{85} \mathrm{Rb}^{+}$and its amount quantified by atomic absorption spectroscopy [17]. However, both assays suffer from poor temporal resolution.

In this report, we describe the development of a fluorescent-based influx assay that can accurately and rapidly measure the activity of a chimeric NKCC2 construct expressed at the apical membrane of polarized epithelial cells.

In agreement with previous workers $[5,6]$ we found that the presence of the $\mathrm{N}$-terminus of $\mathrm{NKCC} 2$ in any construct appears to prevent functional expression in HEK-293 cells as well as stable expression in epithelial cells such as MDCK and LLC-PK1 cells.

Indeed, we circumvent this problem by the use of a chimeric NKCC1-NKCC2 construct, which shares crucial features of either NKCC1 or NKCC2 isoforms, such as the high predisposition to the stable expression in epithelial cells and the selective localization at the apical membrane, respectively.

Our functional assay is based on the use of Thallium $\left(\mathrm{Tl}^{+}\right)$, instead of $\mathrm{Rb}^{+}$, as the $\mathrm{K}^{+}$tracer. This is possible because of the selective permeability of all $\mathrm{K}^{+}$ion channels and transporters for $\mathrm{Tl}^{+}$and the strong driving force for $\mathrm{Tl}^{+}$entry into the cells when the channels-transporters are activated [17-19].

We took advantage of the availability of a $\mathrm{Tl}^{+}$-sensitive, fluorescence-based ion flux indicator successfully used in a high-throughput assay as previously reported [20]. $\mathrm{Tl}^{+}$binds with high affinity to the corresponding $\mathrm{K}^{+}$ ion site on $\mathrm{c}-\mathrm{NKCC} 2$ and once transported within the cytoplasm, where it is naturally absent, it associates with the halide-sensitive fluorescent dye, causing a fluorescence increase that can be detected by the Flex station Device. The most important advantages of this method are 1- the high temporal resolution compared to the end point assays, 2- a more direct measurement of the NKCC transport activity compared to the indirect assays.

\section{Results}

\section{Characterization of the cellular model}

We sought to assess the feasibility of this assay in the renal epithelial LLC-PK1 cells stably transfected with a previously characterized chimeric NKCC2 construct (c-NKCC2) $[6,21,22]$. This cell line was tested for the polarized expression of the Na-K-ATPase and c-NKCC2 by confocal immunofluorescence when grown on coverslip, a condition that mimics that of cells grown in the 96 well microplates. C-NKCC2 was detected using an antibody against the $\mathrm{HA}$ tag, expressed at the $\mathrm{N}$-terminal tail of the protein [6], thus specifically identifying the transfected c-NKCC2 isoform.

As shown in Figure 1A c-NKCC2 (green labeling) and Na-K-ATPase (red labeling) are selectively expressed at the apical and basolateral membrane of LLC-PK1 respectively, demonstrating that in the condition in which cells were assayed for NKCC2 functional activity, LLC-PK1 cells are correctly polarized. Moreover, untransfected LLC-PK1 cells were checked for the endogenous expression of NKCC2 using a specific anti-NKCC2 antibody. As show in Figure 1B, although the expression of the NaK-ATPase was again clearly appreciable (red labeling), the endogenous expression of NKCC2 was undetectable in any cellular compartment.

Of note, the same antibody well recognized the endogenous NKCC2 in rat kidney sections (Figure 1B, inset). In conclusion, the c-NKCC2-transfected LLC-PK1 cells will allows us to follow only the activity of the ectopically expressed c-NKCC2 protein.

\section{$\mathrm{Tl}^{+}$influx assay in mock and c-NKCC2 transfected LLC-PK1 cells}

Mock- and c-NKCC2-transfected LLC-PK1 cells were incubated in chloride- and potassium-free assay buffer in the presence of the FluxOR ${ }^{\mathrm{TM}}$ dye to simultaneously achieve both activation of the c-NKCC2 cotransporter and cell loading with the dye (Figure 2A). The absence of $\mathrm{K}^{+}$ from the assay buffer was necessary to avoid the competition with $\mathrm{Tl}^{+}$on c-NKCC2. Then we analyzed the $\mathrm{Tl}^{+}$and $\mathrm{Cl}^{-}$influx in these cells by monitoring the effect of successive addition of $\mathrm{Tl}^{+}$and $\mathrm{Cl}^{-}$on the fluorescence signal dynamics (Figure $2 \mathrm{~B}$ ) as recorded by the Flexa microplate reader.

The kinetics of the fluorescence signal was recorded over a period of $90 \mathrm{~s}$ (Figure 3A). In the absence of $\mathrm{Cl}^{-}$in the assay buffer, $\mathrm{Tl}^{+}$addition did not induce any increase in fluorescence suggesting that, in this experimental condition, $\mathrm{Tl}^{+}$was not transported within the cells through any other $\mathrm{K}^{+}$transporter expressed at the apical side of the monolayer. Moreover, this result confirms that, in this experimental condition, LLC-PK1 cells form a tight epithelium that makes the basolateral $\mathrm{Na}^{+}-\mathrm{K}^{+}$-ATPase inaccessible to the $\mathrm{Tl}^{+}$ions added at the apical side. 


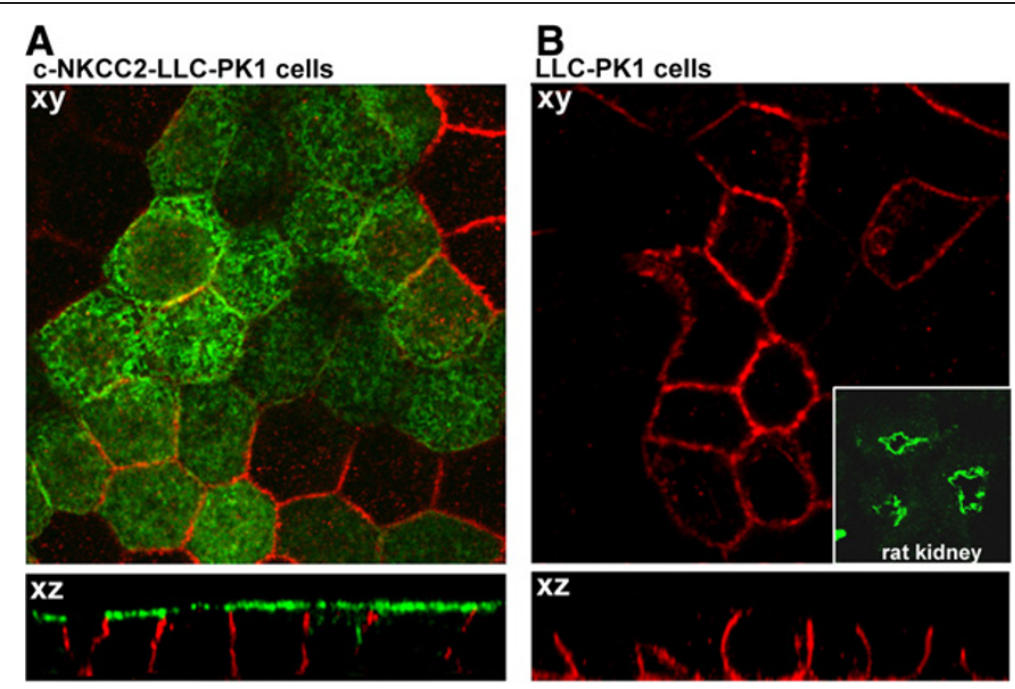

Figure 1 A) Immunofluorescence confocal analysis of Na-K-ATPase (red signal) and c-NKCC2 (green signal) in c-NKCC2-transfected LLC-PK1 cells grown on coverslips. The merged signal of planar xy and xz projections was depicted. Na-K-ATPase and c-NKCC2 are selectively expressed at the basolateral and apical membrane respectively. B) Immunofluorescence confocal analysis of Na-K-ATPase (red signal) and the endogenous NKCC2, (green signal) in untransfected LLC-PK1 cells grown on coverslips. The merged signal of planar xy and xz projections was depicted. Na-K-ATPase was selectively expressed at the basolateral membrane whereas the endogenous NKCC2 was absent. Inset:

Immunolocalization of the endogenous NKCC2 in a rat kidney section.

Interestingly, a robust $\mathrm{Tl}^{+}$influx was observed only after $\mathrm{Cl}^{-}$addition in C-NKCC2- expressing LLC-PK1 cells but not in mock-transfected LLC-PK1 cells in which only a weak increase in fluorescence was observed (Figure 3A, mock and c-NKCC2-LLC-PK1 cells). Indeed, as predicted by the ectopic expression of c-NKCC cotransporter, $\mathrm{Tl}^{+}$transport within the cell required the presence of external $\mathrm{Cl}^{-}$.

The c-NKCC2-driven fluorescence signal recorded after $\mathrm{Cl}^{-}$addition displays a rapid linear increased phase

\section{A}
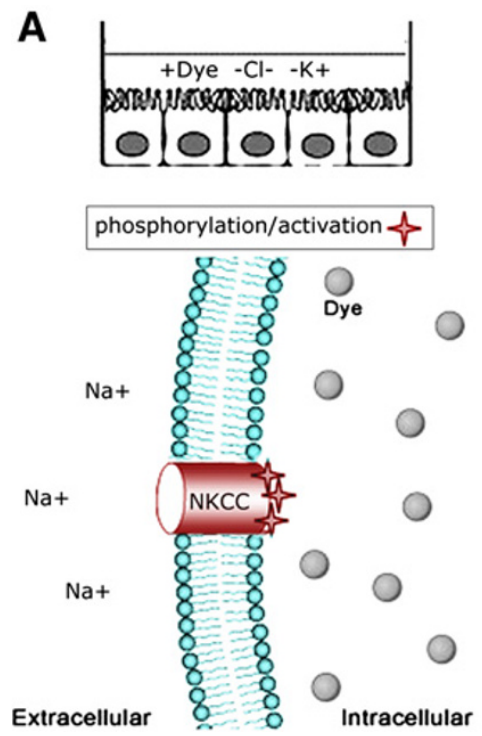

B
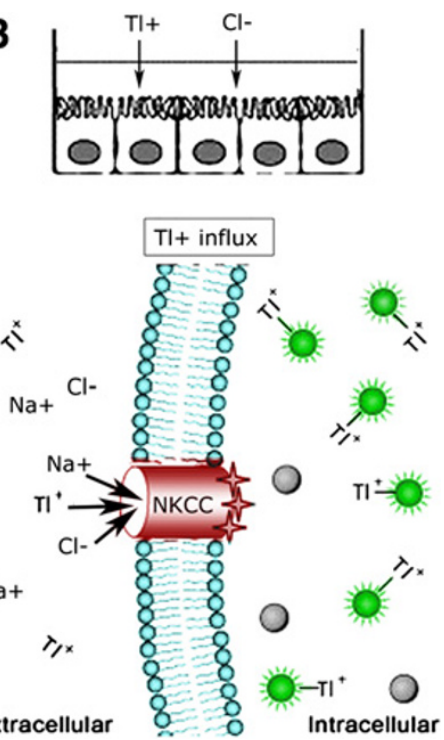

Figure 2 Scheme of the experimental design modified from http://probes.invitrogen.com/media/pis/mp10016.pdf. A) Cells cultured in the 96 well plate were preincubated with the $\mathrm{Tl}^{+}$-sensitive FluxOR ${ }^{\mathrm{TM}}$ dye (Dye) in a $\mathrm{Cl}^{-}$-free loading buffer $\left(-\mathrm{Cl}^{-}\right.$) to promote $\mathrm{C}-\mathrm{NKCC}$ cotransporter activation. The loading buffer was also $\mathrm{K}^{+}$-free $\left(-\mathrm{K}^{+}\right)$to rule out the competition of $\mathrm{K}^{+}$with $\mathrm{Tl}^{+}$at the binding site onto the c-NKCC cotransporter. FluxOR ${ }^{\mathrm{TM}}$, loaded within the cytoplasm, is quenched in the absence of $\mathrm{Tl}^{+}$ions. B) The assay is started with the following addition of $\mathrm{Tl}^{+}$and $\mathrm{Cl}^{-}$in the assay plate. $\mathrm{Tl}^{+}$flows inside the cells along with $\mathrm{Na}^{+}$and $\mathrm{Cl}^{-}$through the c-NKCC cotransporter. Upon binding to $\mathrm{Cytosolic}^{+}{ }^{+}$, the $\mathrm{FluxOR}^{\mathrm{TM}}$ dye exhibits a strong increase in fluorescence intensity. 


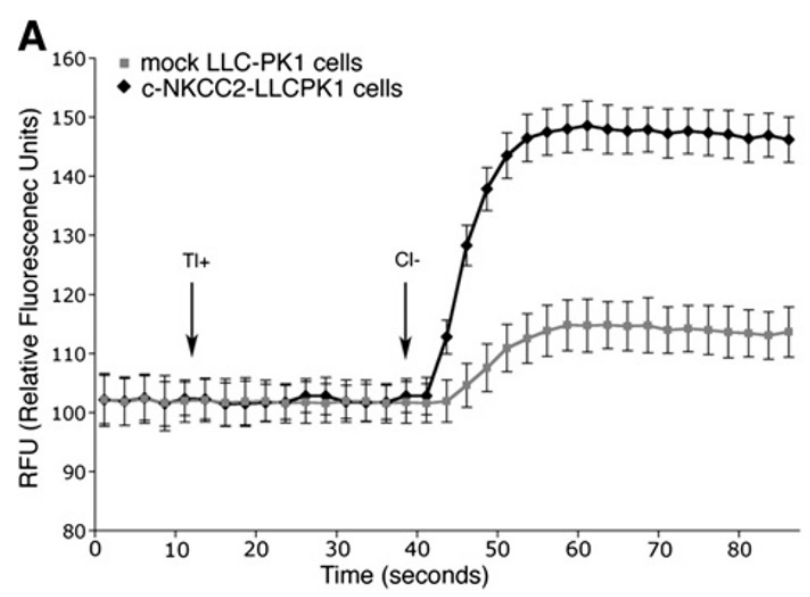

B
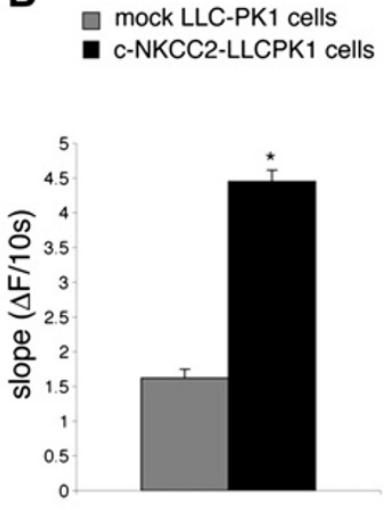

Figure $3 \mathrm{TI}^{+}$influx assay in LLC-PK1 cells. A) Mean signal traces (average from 6 wells) obtained with the fluorometric imaging plate reader (FlexStation). LLC-PK1 cells either mock-transfected or stable transfected with c-NKCC2 construct were shown. $\mathrm{Tl}^{+}$influx was initiated by $\mathrm{Cl}^{-}$ addition. A robust $\mathrm{Cl}^{-}$-dependent $\mathrm{Tl}^{+}$influx was observed in c-NKCC2-transfected but not in mock-transfected LLC-PK1 cells. B) The initial rate of $\mathrm{Tl}^{+}$influx registered during the assay shown in A was reported. The rate of $\mathrm{TI}^{+}$influx was increased by about 3-fold upon c-NKCC2 expression in LLC-PK1 cells. Values are means \pm SE of 3 independent experiments. Student's $t$ test for unpaired data, ${ }^{*} p<0.0001$.

within the first 10-15 s, followed by a slower increase and a plateau phase. In our experiments kinetic measurement of the transporter activity followed the same fundamental concepts and principles as measurement of enzyme activity. Thus, c-NKCC2 activity was most accurately represented by the initial rate of $\mathrm{Tl}^{+}$transport, which can be calculated using the initial linear phase of the curve. The initial rate of $\mathrm{Cl}^{-}$-dependent $\mathrm{Tl}^{+}$ influx observed in c-NKCC2 transfected cells is about 3 -fold over the background signal registered in mocktransfected LLC-PK1 cells (Figure 3B).
To further confirm that the observed $\mathrm{Tl}^{+}$influx was actually mediated by c-NKCC2, we assessed the effects of the known inhibitor of NKCC cotransporters, Furosemide.

As shown in Figure 4A, in c-NKCC2-transfected cells, $30 \mathrm{~min}$ of Furosemide preincubation $(50 \mu \mathrm{M})$ (Furo) clearly inhibited the $\mathrm{Cl}^{-}$-dependent $\mathrm{Tl}^{+}$influx compared to control untreated cells (CTR). Calculation of the initial rate of fluorescence increase showed that $\mathrm{Tl}^{+}$ influx was inhibited by Furosemide treatment by about 3 fold compared to control conditions (Figure 4B).

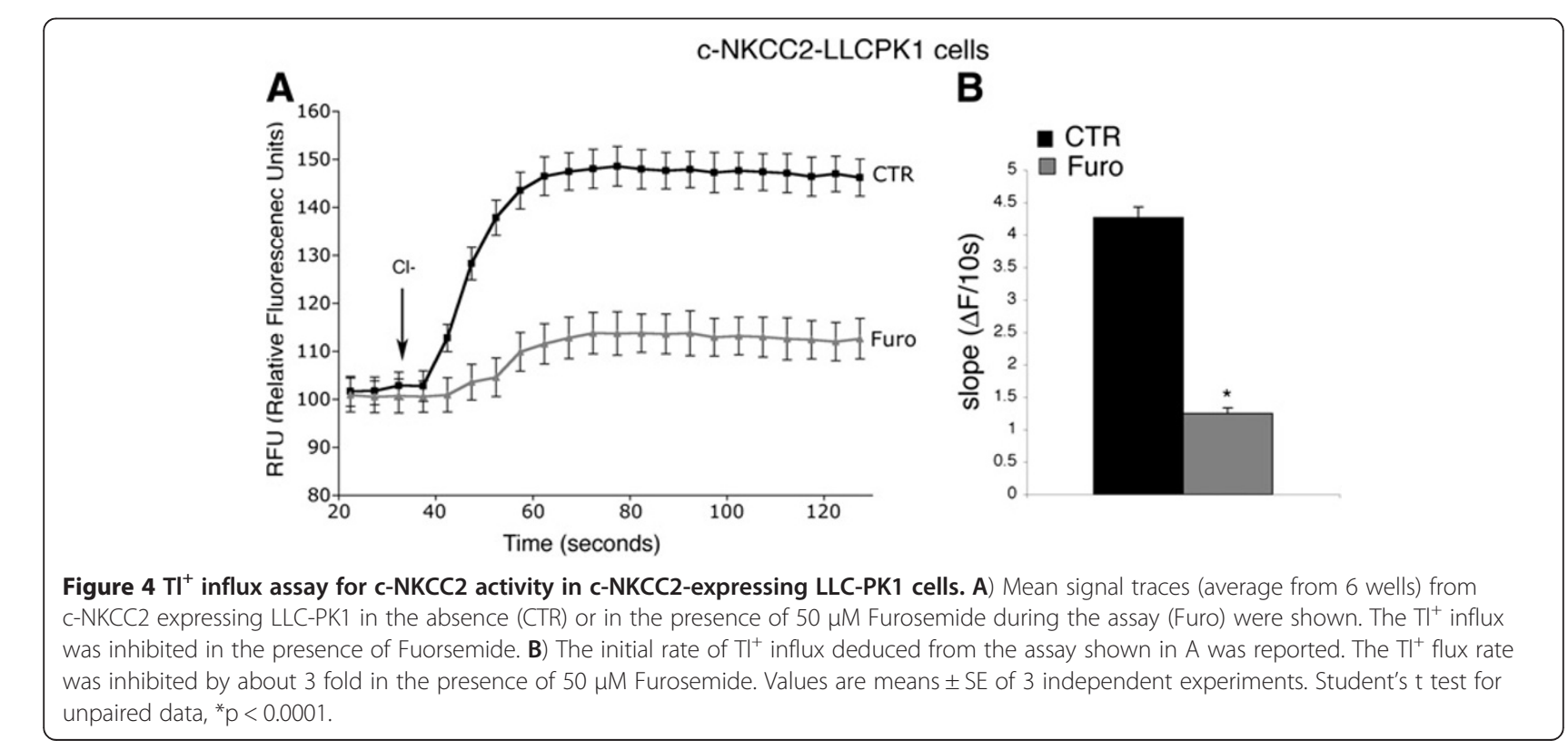


Interestingly though, the $\mathrm{Tl}^{+}$influx was not completely abolished even in the presence of higher Furosemide concentrations (data not shown) and it was comparable to that detected in mock-transfected LLC-PK1 cells, likely suggesting the presence of an endogenous furosemide insensitive $\mathrm{Cl}^{-}$-dependent $\mathrm{Tl}^{+}$influx in LLC-PK1 cells.

To further verify this hypothesis, furosemide was tested on mock-transfected LLC-PK1 cells. As shown in Figure 5 the weak increase in fluorescence was observed after $\mathrm{Cl}^{-}$addition in mock-transfected LLC-PK1 cells, regardless of whether they were only preincubated with or continuously exposed to furosemide, suggesting the endogenous expression of a Furosemide-insensitive $\mathrm{Tl}^{+}$ transport in LLC-PK1 cells (Figure 5, Furosemide).

Although the $\mathrm{Tl}^{+}$flux observed in these cells was $\mathrm{Cl}^{-}$dependent, we definitively excluded that it was mediated by the $\mathrm{Na}$-K-ATPase since it was not abolished by the presence of Ouabain during the assay (Figure 5, Ouabain).

\section{External $\mathrm{Cl}^{-}$dependency of the c-NKCC2-mediated $\mathrm{TI}^{+}$ transport}

To assess the dependency of the c-NKCC2-mediated $\mathrm{Tl}^{+}$transport on external $\mathrm{Cl}^{-}$concentration, buffers with different final concentrations $(0-135 \mathrm{mM})$ of $\mathrm{Cl}^{-}$, and in which $\mathrm{NaCl}$ was replaced by $\mathrm{Na}$-gluconate to maintain appropriate osmolarity, were administered during the assay after $\mathrm{Tl}^{+}$addition. As expected by the expression of NKCC cotransporter, the initial rate of $\mathrm{Tl}^{+}$transport increased proportionately with increasing external concentration of $\mathrm{Cl}^{-}$(Figure 6A). The initial rate of $\mathrm{Tl}^{+}$influx at each $\mathrm{Cl}^{-}$concentration was calculated and plotted against 3, 10, 30, 70, 100, $135 \mathrm{mM}$ extracellular $\mathrm{Cl}^{-}$concentrations. The obtained values were fitted by the model of activation at a single

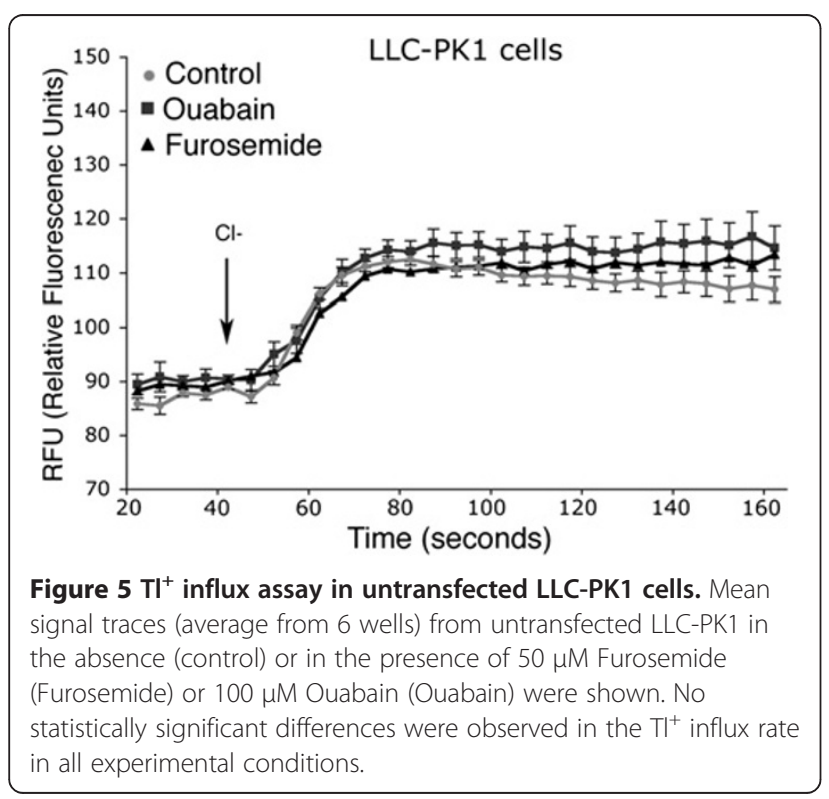

site. A calculation of the affinity of c-NKCC2 for external $\mathrm{Cl}^{-}$revealed a Michaelis-Menten Constant $\mathrm{Km}$ at 23.4 $(n=8)$ (Figure 6B).

\section{Discussion}

Technological advances in the past few years have indicated the fluorescence-based methods as among the most useful detection strategies for high throughput screening of drugs. The main advantages associated with this approach are temporal resolution, high sensitivity, simplification of the experimental procedures and miniaturization of the assay and time optimization. In addition, screening assays that are based on optical readout including fluorescence are commonly more robust, suitable for automation, and less expensive than those utilizing radioisotopes or electrophysiological techniques.

A fluorescence-based $\mathrm{Tl}^{+}$influx assay has been recently developed to rapidly measure the activity and to screen for positive modulators of a member of the $S L C$ superfamily, $\mathrm{KCC} 2$, in mammalian cells, suggesting the feasibility of the $\mathrm{Tl}^{+}$influx through the K-cotransporters as measure of $\mathrm{K}^{+}$fluxes [19].

In the present work we described a fluorescent-based $\mathrm{Tl}^{+}$transport assay that measured the activity of the NKCC2 chimeric construct c-NKCC2, stably expressed at the apical membrane of renal epithelial cells. Although the assay is based on an existing $\mathrm{Tl}^{+}$-flux based kit, it has been for the first time adapted to measure the activity of NKCC cotransporters. The assay has been designed in a highthroughput format and has high temporal resolution. The feasibility of the essay was granted by the fact that NKCC cotransporters should be able to transport $\mathrm{Tl}^{+}$ions instead $\mathrm{K}^{+}$and that fluorescent $\mathrm{Tl}^{+}$flux indicators are commercially available. In this assay we used the FluxOR ${ }^{\mathrm{TM}} \mathrm{Tl}^{+}$ sensitive dye, which is roughly 10 -fold more $\mathrm{Tl}^{+}$sensitive, requiring much lower $\mathrm{Tl}^{+}$concentrations for a larger signal window compared to other $\mathrm{Tl}^{+}$dyes [20]. Importantly, this means that the assay can be carried out in physiological saline with normal chloride concentrations. This was an important limitation of other $\mathrm{Tl}^{+}$sensitive dyes, for which chloride-free conditions were necessitated by the solubility coefficient of Thallium chloride, which is about $4 \mathrm{mM}$ at physiological $\mathrm{pH}$.

The activity of NKCC cotransporters is strongly dependent on the phosphorylation of a group of threonine residues in a regulatory domain in its $\mathrm{N}$-terminus $[13,23]$. One potent stimulus promoting phosphorylation is a fall in cell chloride concentration that causes phosphorylation and activation of SPAK and OSR1, kinases that phosphorylate threonine residues in NKCC regulatory domain $[24,25]$.

Upon the transporter activation, obtained in chloridefree buffers, we have been able to measure a robust $\mathrm{Cl}^{-}$-dependent $\mathrm{Tl}^{+}$influx in LLC-PK1 cells stably 


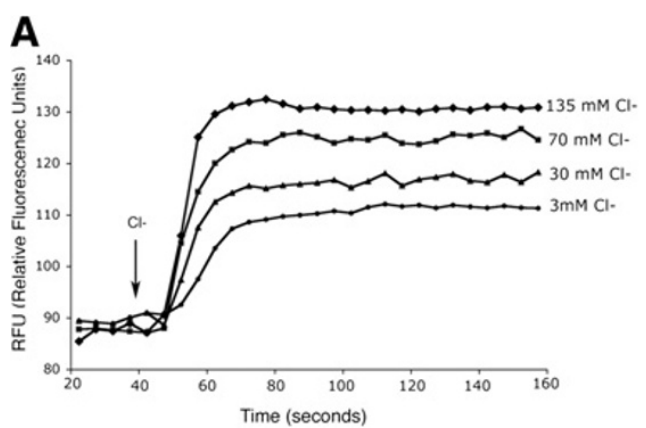

B

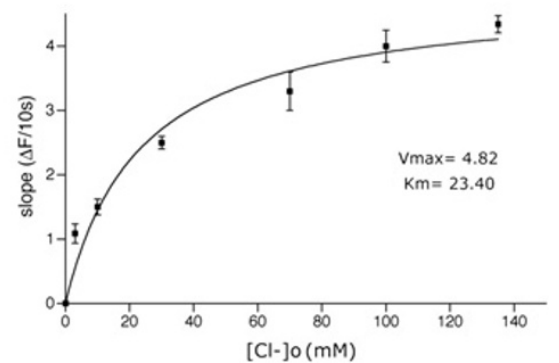

Figure 6 Dependency of c-NKCC2-mediated $\mathrm{Tl}^{+}$influx on external $\mathrm{Cl}^{-}$in c-NKCC2-expressing LLC-PK1 cells. A) $\mathrm{Tl}^{+}$influx assays were conducted in assay buffer with varying concentrations of $\mathrm{Cl}^{-}$, in which $\mathrm{Cl}^{-}$was replaced by gluconate. Representative raw signal traces after 3, 30, $70,135 \mathrm{mM} \mathrm{Cl}^{-}$addition were reported. B) The initial rate of $\mathrm{Tl}^{+}$influx at the different $\mathrm{Cl}^{-}$concentrations was calculated and plotted against 3, 10, $30,70,100,135 \mathrm{mM}\left[\mathrm{Cl}^{-}\right]_{\text {. }}$. Values are means $\pm \mathrm{SE}$ of 3 independent experiments and the curve represents the best fit of data to a model of activation at a single site. Michaelis-Menten constant Km was deduced.

transfected with the NKCC2 chimeric construct, c-NKCC2.

A number of evidences led us to believe that the $\mathrm{Tl}^{+}$influx measured in our experimental conditions is actually mediated by c-NKCC2. First, substantial $\mathrm{Tl}^{+}$influx was observed exclusively in c-NKCC2-expressing LLC-PK1 cells but not in mock-transfected cells. Second, the $\mathrm{Tl}^{+}$influx exhibited dependency on external $\mathrm{Cl}^{-}$concentrations, a common hallmark of NKCC cotransporters and SLCT12 transporter family in general. Third, the $\mathrm{Tl}^{+}$influx was inhibited by the NKCC inhibitor, Furosemide. Based on these strong indications, we can safely conclude the $\mathrm{Tl}^{+}$ influx observed in our assay is due to c-NKCC2 activity.

Interestingly, we observed a residual $\mathrm{Tl}^{+}$influx in LLCPK1 cells in the presence of either NKCC or Na-K-ATPase inhibitors Furosemide and Ouabain respectively.

Accordingly, an ouabain- and bumetanide- insensitive ${ }^{86} \mathrm{Rb}^{+}$influx has been previously observed in LLC-PK1 cells, suggesting the presence of unknown $\mathrm{K}^{+}$uptake pathways different from NKCC and Na-K-ATPase in these cells [26].

It is possible that LLC-PK1 cells express an endogenous KCC-like activity, although there are no indications for a constitutive expression of KCC transporters in LLC-PK1 cells, and this activity would contribute to the $\mathrm{Tl}^{+}$influx signal. The effect of KCC inhibitors should be tested to definitively address the issue of whether $\mathrm{KCC}$ is actually involved in the residual $\mathrm{Tl}+$ influx observed in LLC-PK1 cells. However this issue is beyond the scope of this work.

Using different $\mathrm{Cl}^{-}$concentrations in the assay buffer we have been able to measure the affinity of the chimeric c-NKCC2 protein for the external $\mathrm{Cl}^{-}$concentration $\left(\left[\mathrm{Cl}^{-}\right]_{\mathrm{o}}\right)$ $(\mathrm{Km}=23.4 \mathrm{mM})$, which is comparable to that measured for NKCC1 using the ${ }^{86} \mathrm{Rb}^{+}$flux assay [27], found to be $31 \mathrm{mM}$, and different from that of the NKCC2 counterpart, found to be $12 \mathrm{mM}$ [9].
This value was predictable since this chimera was generated exchanging the $\mathrm{C}$-terminal apical sorting domain of the B mammalian isoform of NKCC2 into the NKCC1 backbone [6]. Indeed, the transmembrane domain of the chimeric construct, responsible for ions transport, belongs entirely to the NKCC1 isoform, thus accounting for the affinity value for $\mathrm{Cl}^{-}$comparable to that measured for NKCC1 by ${ }^{86} \mathrm{Rb}^{+}$influx assay, [27]. One of the critical features of such an assay is its ability to reproduce the results obtained with previously characterized methods.

The obtained $\mathrm{Km}$ value for $\mathrm{c}-\mathrm{NKCC} 2$ showed that the NKCC activity measured by this $\mathrm{Tl}^{+}$influx assay shows comparable kinetic coefficients to those determined with ${ }^{86} \mathrm{Rb}^{+}$influx assay, thus farther validating the method.

Of note, the kinetic behaviour of c-NKCC2-mediated $\mathrm{Tl}^{+}$influx in dependence of $\left[\mathrm{Cl}^{-}\right]_{\mathrm{o}}$, did not follow the cooperative kinetics of the two $\mathrm{Cl}^{-}$binding sites as predicted by different functional assays $[5,8,27]$. However, the issue of whether the NKCC cotransporters family binds ions in a preferred order or displays cooperativity of binding is still far from resolved.

Several studies failed to demonstrate that the two $\mathrm{Cl}^{-}$ binding sites behave cooperatively suggesting that the kinetic properties of NKCC-mediated $\mathrm{Cl}^{-}$influx depends on the type of NKCC isoforms, species, cellular models and experimental approaches used in the assays (for details see review [28]). In agreement, Brumback et al. showed that in pyramidal neurons, NKCC1 transport activity in dependence of $\left[\mathrm{Cl}^{-}\right]_{\mathrm{o}}$ fits the Michaelis-Menten kinetic model [29].

Indeed, the thermodynamics of $\mathrm{Tl}^{+}$influx in dependence of $\left[\mathrm{Cl}^{-}\right]_{\mathrm{o}}$ showed in this study could due to the specific chimeric construct, the cell type and the experimental approach based on fluorescent time courses rather than an end-point measurement of a radioactive compound influx. 
We setup this method using polarized epithelial LLC-PK1 cells grown on 96 wells plates and expressing a chimeric $\mathrm{NKCC} 2$ at the apical membrane thus reproducing in vitro NKCC2-renal expressing polarized cells.

Although both $\mathrm{NKCC} 1$ and $\mathrm{NKCC} 2$ are sensitive to loop-diuretics, the renal isoform NKCC2 is the main physiological target of these drugs in the treatment of hypertension. Indeed, the expression of NKCC2 in renal epithelial cells better recapitulates the physiological context where to study the regulation and the pharmacological modulation of this cotransporter.

In other systems, however, the bumetanide-sensitive $\mathrm{Tl}^{+}$uptake has been measured in primary neurons from dorsal root ganglions, likely mediated by the neuronal NKCC1 isoform [30] suggesting the feasibility of this $\mathrm{Tl}^{+}$assay also for the analysis of the NKCC1 isoform.

Moreover, in line of principle, this method could also be applicable to non-polarized mammalian cells such as HEK293, transfected with any NKCC cotransporter constructs. In fact, HEK293 cells have been successfully used in the $\mathrm{K}^{+}$channel functional assay using $\mathrm{Tl}^{+}$-sensitive dye in the Flex station device [18] and efficiently transfected with different NKCC constructs displaying the expression of resulting proteins on the overall plasma membrane [5].

It has to be underlined that the $\mathrm{Tl}^{+}$influx assay offers several significant advantages over the other functional assays measuring NKCC cotransporter activity. Compared to radioactive and non radioactive $\mathrm{Rb}^{+}$flux assays, the $\mathrm{Tl}^{+}$influx assay offers high temporal resolution with measurement of real-time changes in ion flux profile within the initial seconds, when ion transport is occurring at a linear rate, rather than minutes, as in the $\mathrm{Rb}^{+}$flux assays in which the end point $\mathrm{Rb}^{+}$ intracellular accumulation is measured. Importantly, as a continuous assay, the $\mathrm{Tl}^{+}$flux assay is easier to perform and inherently offers improved sensitivity and accuracy over endpoint assay. Compared to a $\mathrm{NH}_{4}^{+}$ uptake assay measured with a $\mathrm{pH}$-sensitive fluorescent dye, the $\mathrm{Tl}^{+}$influx assay is direct functional assay with better resolution and sensitivity.

\section{Conclusions}

The new functional assay we described here would be extremely useful in the high-throughput screening and characterization of new NKCC inhibitors as antihypertensive drugs. Moreover, the chimeric NKCC1NKCC2 construct used in this work, functionally expressed at the apical membrane of polarized LLCPK1 cells, will allow us to explore factors that regulates NKCC2 sorting and function in a more physiological context such as a renal epithelial polarized cell system.

\section{Methods}

\section{Reagents}

The FluxOR ${ }^{\mathrm{TM}}$ Thallium detection kit was from Life Technologies $^{\mathrm{TM}}$ (http://www.lifetechnologies.com). All chemicals were purchased from Sigma-Aldrich ${ }^{\circledR}$ (http://www.sigmaaldrich.com).

\section{Cell culture}

c-NKCC2-LLC-PK1 cells were generated as previously described [6] and cultured in DMEM (Life Technologies ${ }^{\mathrm{TM}}$ ) supplemented with $10 \%$ fetal bovine serum (Life Technologies $^{\mathrm{TM}}$ ) and 1\% penicillin-streptomycin (Life Technologies $^{\mathrm{TM}}$ ) in a humidified $5 \% \mathrm{CO}_{2}, 95 \% \mathrm{O}_{2}$ incubator at $37^{\circ} \mathrm{C}$.

\section{Immunofluorescence}

c-NKCC2-LLC-PK1 cells were grown on glass coverslips and subjected to immunofluorescence when they reached the confluency. Cells were fixed in cold methanol for $10 \mathrm{~min}$. After three washes in phosphate-buffered saline (PBS), cells were blocked in saturation buffer (1\% bovine serum albumine in PBS) for $20 \mathrm{~min}$ at room temperature (RT) and incubated with the primary antibodies for $2 \mathrm{~h}$ at RT in saturation buffer. After 3 washes in PBS cells were incubated with the appropriate Alexafluor conjugated secondary antibodies (Life Technologies ${ }^{\mathrm{TM}}$ ) for $1 \mathrm{~h}$ at RT. Primary antibodies used were: polyclonal anti-HA antibody (Covance, 1:1000) to detect c-NKCC2, the monoclonal anti- $\alpha$ subunit of $\mathrm{Na}^{+} / \mathrm{K}^{+}$ATPase antibody for the detection of the endogenous Na-K-ATPase (Sigma, 1:500) and the polyclonal anti-NKCC2 antibody (Millipore, 1:500) for the detection of endogenous NKCC2 in both LLC-PK1 cells and rat kidney slides. Confocal images were obtained with a laser scanning fluorescence microscope Leica TSC-SP2 (HCX PL APO, ×63/1.32-0.60 oil objective); 8 -bit images were saved at $1024 \times 256$ and acquired using the Leica Confocal Software ${ }^{\circledR}$.

\section{Fluorescence acquisition}

Fluorescence signal was acquired using the FlexStation II devise from Molecular Devices (http://www. moleculardevices.com/), MDS Analytical Technologies, USA, equipped to perform functional cellular assays and to analyze real time fluorescence kinetic data in the 96-well format. The instrument consists of an incubated cabinet with fluorometer and integrated 96 channel pipettor which is able to transfer compounds from one compound microplate to the assay plate, allowing rapid kinetic assays. Data acquisition was performed by SoftMax Pro software.

\section{$\mathrm{Tl}^{+}$influx assay by the FlexStation device}

Cells were seeded in 96-well, black-walled, clear-bottomed (Corning, http://www.corning.com) at a density of $5 \times 10^{4}$ 
cells per well $48 \mathrm{~h}$ before the assay at which time cells were $100 \%$ confluent.

On the day of the assay, the cell culture medium was replaced with $100 \mu \mathrm{l} /$ well of the FluxOR ${ }^{\mathrm{TM}}$ chloride-free buffer (Component E) containing the $\mathrm{Tl}^{+}$-sensitive fluorogenic indicator dye, FluxOR ${ }^{\mathrm{TM}}$ reagent (Component A) and Probenecid (Component D) according to the manufacturer's instructions. The FluxOR ${ }^{\mathrm{TM}}$ reagent is a non fluorescent indicator dye, which is loaded into cells as a membrane-permeable acetoxymethyl (AM)-ester. Once inside the cell, the non-fluorescent AM ester form of the FluxOR $^{\mathrm{TM}}$ dye is cleaved by endogenous esterases into a fluorogenic $\mathrm{Tl}^{+}$-sensitive indicator. The $\mathrm{Tl}^{+}$-sensitive form is retained within the cytosol and its extrusion is inhibited by water-soluble Probenecid, which blocks organic anion pumps.

Dye loading was allowed to proceed for $1 \mathrm{~h}$ at $37^{\circ} \mathrm{C}$, then cells were washed twice in $100 \mu \mathrm{l} /$ well assay buffer (in $\mathrm{mM}$ : 135 Na-gluconate, $1 \mathrm{mM} \mathrm{MgCl}, 1 \mathrm{mM} \mathrm{Na} 2 \mathrm{SO}$, $1 \mathrm{mM} \mathrm{CaCl}_{2}, 15 \mathrm{mM}$ Na-HEPES, pH 7,4). The wash buffer was discarded, cells were left in $100 \mu$ of assay buffer and loaded onto the FlexStation device. When required, $50 \mu \mathrm{M}$ furosemide was added in all these steps.

Ions to be transported by NKCC2 $\left(\mathrm{Cl}^{-}\right.$and $\left.\mathrm{Tl}^{+}\right)$were prepared in the compound assay plate as $6 \times$ concentrated solutions in the assay buffer to give a final concentration of $135 \mathrm{mM} \mathrm{NaCl}$ and $2 \mathrm{mM} \mathrm{Tl}_{2} \mathrm{SO}_{4}$ after addition in the assay plate.

FluxOR dye was excited at $490 \mathrm{~nm}$ and detected at $520 \mathrm{~nm}$ using dual monochromators. Time course fluorescence data were recorded over a $80 \mathrm{~s}$ period. We assayed each well for $\mathrm{Cl}^{-}$-dependent $\mathrm{Tl}^{+}$transport by continuously recording fluorescence for $15 \mathrm{~s}$ (baseline), then for $15 \mathrm{~s}$ after rapid automated addition of $20 \mu \mathrm{L}$ of $6 \times \mathrm{Tl}_{2} \mathrm{SO}_{4}$ and for $40 \mathrm{~s}$ after automated addition of $20 \mu \mathrm{L}$ of $6 \times \mathrm{NaCl}$. To optimize the number of data points, we set the instrument to read out sequentially the top half of the plate and the bottom one. Each time point was, thus, obtained every $2 \mathrm{~s}$. The initial rate of $\mathrm{Tl}^{+}$ transport was deduced by analyzing the linear increase of fluorescent signals within the initial $15 \mathrm{~s}$ following $\mathrm{NaCl}$ addition.

\section{Data analysis}

Relative initial rates of $\mathrm{Tl}^{+}$transport were calculated as the slope of the linear kinetic phase of fluorescent signal within the first $20 \mathrm{~s}$ after $\mathrm{Cl}$ - addition.

Data were collected from at least 6 trials for each concentration and fit with a single-site binding curve using Graphpad prism software (Graphpad software). MichaelisMenten constant $\mathrm{Km}$ was deduced.

\section{Authors' contributions}

MC designed the experiments, developed the experimental work, performed data analyzes and wrote the paper. FR conducted the TI + influx assays. ST provided a technical support. GP conducted microscopy confocal analysis. MS supervised the study, and supervised the writing of the article. All authors read and approved the final manuscript.

\section{Authors' information}

The corresponding author Carmosino M, is currently an Associate Professor in Physiology at the University of Basilicata, Italy. She has been a Faculty Member of the Department of Cellular and Molecular Physiology at the Yale University School of Medicine from 2006 to 2010, where she made important observations on the polarized trafficking and ion transport kinetics of the renal cotransporter NKCC2 (Carmosino et al. Mol Biol Cell. 2008 Oct; 19(10):4341-51; Pedersen M, Carmosino M, Forbush B., J Biol Chem. 2008 Feb 1;283(5):2663-74; Carmosino et al. Mol Biol Cell. 2010 Nov 15; 21(22): 398597). She collaborated with Professor Biff Forbush and Professor Mike Caplan, who made profound contributions on the discovery and characterization of the NKCC cotransporters and developed automatized devices to measure ion fluxes mediated by this cotransporter family in oocytes and mammalian cells.

\section{Acknowledgements}

This work was supported by the Italian grant PRIN 20078ZZMZW (to M.S.) and by Fondo per gli Investimenti della Ricerca di Base-Rete Nazionale di Proteomica (RBRN07BMCT_009).

Received: 18 September 2012 Accepted: 28 February 2013 Published: 18 March 2013

\section{References}

1. Gamba G: Molecular physiology and pathophysiology of electroneutral cation-chloride cotransporters. Physiol Rev 2005, 85(2):423-493.

2. Flatman PW: Cotransporters, WNKs and hypertension: important leads from the study of monogenetic disorders of blood pressure regulation. Clin Sci (Lond) 2007, 112(4):203-216.

3. Payne JA, Forbush B 3rd: Alternatively spliced isoforms of the putative renal $\mathrm{Na}-\mathrm{K}-\mathrm{Cl}$ cotransporter are differentially distributed within the rabbit kidney. Proc Natl Acad Sci U S A 1994, 91(10):4544-4548.

4. Gagnon E, Forbush B, Flemmer AW, Gimenez I, Caron L, Isenring P: Functional and molecular characterization of the shark renal $\mathrm{Na}-\mathrm{K}-\mathrm{Cl}$ cotransporter: novel aspects. Am J Physiol Renal Physiol 2002, 283(5):F1046-F1055.

5. Isenring $P$, Jacoby SC, Payne JA, Forbush B 3rd: Comparison of $\mathrm{Na}-\mathrm{K}-\mathrm{Cl}$ cotransporters. NKCC1, NKCC2, and the HEK cell Na-L-Cl cotransporter. J Biol Chem 1998, 273(18):11295-11301.

6. Carmosino M, Gimenez I, Caplan M, Forbush B: Exon loss accounts for differential sorting of $\mathrm{Na}-\mathrm{K}-\mathrm{Cl}$ cotransporters in polarized epithelial cells. Mol Biol Cell 2008, 19(10):4341-4351.

7. Benziane B, Demaretz S, Defontaine N, Zaarour N, Cheval L, Bourgeois S, Klein C, Froissart M, Blanchard A, Paillard M, et al: NKCC2 surface expression in mammalian cells: down-regulation by novel interaction with aldolase B. J Biol Chem 2007, 282(46):33817-33830.

8. Gagnon E, Bergeron MJ, Daigle ND, Lefoll MH, Isenring P: Molecular mechanisms of cation transport by the renal $\mathrm{Na}+-\mathrm{K}+-\mathrm{Cl}-$ cotransporter: structural insight into the operating characteristics of the ion transport sites. J Biol Chem 2005, 280(37):32555-32563.

9. Gimenez I, Forbush B: The residues determining differences in ion affinities among the alternative splice variants $F, A$, and $B$ of the mammalian renal Na-K-Cl cotransporter (NKCC2). J Biol Chem 2007, 282(9):6540-6547.

10. Hoffmann EK, Lambert IH, Pedersen SF: Physiology of cell volume regulation in vertebrates. Physiol Rev 2009, 89(1):193-277.

11. Lebeau C, Hanaoka K, Moore-Hoon ML, Guggino WB, Beauwens R, Devuyst $\mathrm{O}$ : Basolateral chloride transporters in autosomal dominant polycystic kidney disease. Pflugers Arch 2002, 444(6):722-731.

12. Orlov SN: NKCC1 as a regulator of vascular tone and a novel target for antihypertensive therapeutics. Am J Physiol Heart Circ Physiol 2007, 292(5):H2035-H2036.

13. Darman $\mathrm{RB}$, Forbush $\mathrm{B}$ : A regulatory locus of phosphorylation in the $\mathrm{N}$ terminus of the Na-K-Cl cotransporter, NKCC1. J Biol Chem 2002, 277(40):37542-37550. 
14. Isenring P, Jacoby SC, Chang J, Forbush B: Mutagenic mapping of the $\mathrm{Na}-\mathrm{K}-\mathrm{Cl}$ cotransporter for domains involved in ion transport and bumetanide binding. J Gen Physio/ 1998, 112(5):549-558.

15. Monette MY, Rinehart J, Lifton RP, Forbush B: Rare mutations in the human Na-K-Cl cotransporter (NKCC2) associated with lower blood pressure exhibit impaired processing and transport function. Am J Physiol Renal Physiol 2011, 300(4):F840-F847.

16. Zaarour N, Defontaine N, Demaretz S, Azroyan A, Cheval L, Laghmani K: Secretory carrier membrane protein 2 regulates exocytic insertion of NKCC2 into the cell membrane. J Biol Chem 2011, 286(11):9489-9502.

17. Karczewski J, Kiss L, Kane SA, Koblan KS, Lynch RJ, Spencer RH: Highthroughput analysis of drug binding interactions for the human cardiac channel, Kv1.5. Biochem Pharmacol 2009, 77(2):177-185.

18. Schmalhofer WA, Swensen AM, Thomas BS, Felix JP, Haedo RJ, Solly K, Kiss L, Kaczorowski GJ, Garcia ML: A pharmacologically validated, highcapacity, functional thallium flux assay for the human Ether-a-go-go related gene potassium channel. Assay Drug Dev Technol 2010 8(6):714-726.

19. Zhang D, Gopalakrishnan SM, Freiberg G, Surowy CS: A thallium transport FLIPR-based assay for the identification of KCC2-positive modulators. J Biomol Screen 2010, 15(2):177-184.

20. Weaver CD, Harden D, Dworetzky SI, Robertson B, Knox RJ: A thalliumsensitive, fluorescence-based assay for detecting and characterizing potassium channel modulators in mammalian cells. J Biomol Screen 2004, 9(8):671-677.

21. Carmosino M, Rizzo F, Procino G, Basco D, Valenti G, Forbush B, SchaerenWiemers N, Caplan MJ, Svelto M: MAL/VIP17, a new player in the regulation of NKCC2 in the kidney. Mol Biol Cell 2011, 21(22):3985-3997.

22. Carmosino M, Rizzo F, Procino G, Zolla L, Timperio AM, Basco D, Barbieri C, Torretta S, Svelto M: Identification of moesin as NKCC2-interacting protein and analysis of its functional role in the NKCC2 apical trafficking. Biol Cell 2012, 104:1-19.

23. Vitari AC, Thastrup J, Rafiqi FH, Deak M, Morrice NA, Karlsson HK, Alessi DR: Functional interactions of the SPAK/OSR1 kinases with their upstream activator WNK1 and downstream substrate NKCC1. Biochem J 2006, 397(1):223-231.

24. Lytle C, Forbush B 3rd: Regulatory phosphorylation of the secretory Na-K-Cl cotransporter: modulation by cytoplasmic Cl. Am J Physiol 1996, 270(2 Pt 1):C437-C448.

25. Piechotta K, Lu J, Delpire E: Cation chloride cotransporters interact with the stress-related kinases Ste20-related proline-alanine-rich kinase (SPAK) and oxidative stress response 1 (OSR1). J Biol Chem 2002, 277(52):50812-50819.

26. Amsler K, Kinne R: Photoinactivation of sodium-potassium-chloride cotransport in LLC-PK1/Cl 4 cells by bumetanide. Am J Physiol 1986, 250(5 Pt 1):C799-C806.

27. Isenring P, Forbush B 3rd: Ion and bumetanide binding by the $\mathrm{Na}-\mathrm{K}-\mathrm{Cl}$ cotransporter. Importance of transmembrane domains. J Biol Chem 1997, 272(39):24556-24562.

28. Russel JM: Sodium-Potassium-Chloride Cotransport. Pysiol Rev 2000, 80(1):212-267.

29. Brumback AC, Staley KJ: Thermodynamic Regulation of NKCC1-Mediated $\mathrm{Cl}$ Cotransport Underlies Plasticity of GABAA Signaling in Neonatal Neurons. J Neurosci 2008, 28(6):1301-1312.

30. Geng Y, Hoke A, Delpire E: The Ste20 kinases Ste20-related prolinealanine-rich kinase and oxidative-stress response 1 regulate NKCC1 function in sensory neurons. J Biol Chem 2009, 284(21):14020-14028.

doi:10.1186/1471-2121-14-16

Cite this article as: Carmosino et al:: High-throughput fluorescent-based NKCC functional assay in adherent epithelial cells. BMC Cell Biology 2013 $14: 16$.

\section{Submit your next manuscript to BioMed Central and take full advantage of:}

- Convenient online submission

- Thorough peer review

- No space constraints or color figure charges

- Immediate publication on acceptance

- Inclusion in PubMed, CAS, Scopus and Google Scholar

- Research which is freely available for redistribution

Submit your manuscript at www.biomedcentral.com/submit 